6. Edward W. Boyer, MD, PHD, and Michael Shannonm, M.D., M.P.H. The Serotonin Syndrome. N Engl J Med 2005; 352: 112-1120.

7. Bodner RA, Lynch T, Lewis L, Xahn D. Serotonin Syndrome. Neurology 1995; 45: 219-23.

8. Sternbach H. The Serotonin Syndrome. Am J Psychiatry 1991; 148: 705-13.

\section{Bacteriemias primarias por Pasteurella multocida}

\section{Sr. Director:}

Pasteurella multocida es un cocobacilo gram-negativo que forma parte de la flora orofaríngea de muchos animales (1-3). La colonización por Pasteurella está presente en el $66 \%$ y $90 \%$ de perros y gatos, respectivamente (1). Por ello, es un microorganismo frecuentemente implicado en infecciones cutáneas y de partes blandas originadas por arañazos o mordeduras de estos animales. Se han descrito infecciones graves, como peritonitis bacteriana, meningitis, artritis, neumonía o endocarditis (1-9). Además, pueden aparecer bacteriemias en ausencia de foco evidente de infección en pacientes inmunodeprimidos o en cirróticos (1-8), aunque son infrecuentes. Presentamos dos casos de bacteriemia primaria (sin foco) por P. multocida.

- Caso 1. Un varón de 52 años con cirrosis hepática alcohólica ingresó en nuestro centro por una hemorragia digestiva alta. A la exploración física, la temperatura axilar era de $38,3^{\circ} \mathrm{C}$. Analíticamente presentaba datos sugestivos de hepatopatía crónica (anemia macrocítica, trombopenia, descenso del tiempo de protrombina), así como leucocitosis $\left(16.800 / \mathrm{mm}^{3}\right)$ sin desviación izquierda. La radiografía de tórax, electrocardiograma y gasometría arterial realizadas fueron normales. Se realizó una endoscopia digestiva alta demostrando varices esofágicas grado I sin sangrado activo. Se inició tratamiento con somatostatina y cobertura empírica con amoxicilina-clavulánico. Los hemocultivos resultaron positivos para P. multocida.

-Caso 2. Una mujer de 61 años con antecedentes de colangitis de repetición en relación con una coledocoyeyunostomía ingresó en nuestro centro por sospecha de un nuevo episodio de colangitis. A la exploración física, la temperatura axilar era de $37,8^{\circ} \mathrm{C}$. Analíticamente destacaba leucocitosis $\left(14.640 / \mathrm{mm}^{3}\right)$ con desviación izquierda. El resto de las exploraciones realizadas (incluyendo radiografía de tórax, electrocardiograma y ecografía abdominal) fueron normales. Se inició tratamiento empírico con piperacilina-tazobactam. Los hemocultivos resultaron positivos para $P$. multocida.

Ante los hallazgos de los hemocultivos los pacientes fueron interrogados sobre la presencia de animales domésticos en su entorno. Los dos pacientes poseían un perro, aunque ninguno había sufrido heridas o mordeduras causadas por el animal. Ambos pacientes evolucionaron favorablemente y sin complicaciones.

Las bacteriemias por $P$. multocida son relativamente infrecuentes (1-3). Los aislamientos se producen habitualmente por diseminación hematógena desde una herida causada por un animal o en el contexto de infecciones sistémicas graves por Pasteurella (1-8). Sin embargo, ni el contacto estrecho con un animal, ni la existencia de una puerta de entrada (mordedura, arañazo) son condiciones necesarias para que exista bacteriemia. Así, en diversas series de bacteriemias publicadas se identificó la puerta de entrada en el $88 \%$ (1), $38 \%$ (2) y $40 \%$ (3) de los casos. Asimismo, en una revisión que incluyó 95 casos de bacteriemia, en un $21 \%$ no se demostró contacto con animales (2).

Las bacteriemias por $P$. multocida se relacionan con inmunodepresión, neoplasias malignas, broncopatía crónica y, especialmente, con la cirrosis hepática (1-8). La elevada susceptibilidad a la infección por $P$. multocida en los pacientes cirróticos parece deberse a la disfunción del sistema reticuloendotelial y a la circulación colateral (1-2). La bacteriemia en pacientes cirróticos tiene mayor mortalidad (2).

$P$. multocida se ha aislado del tracto respiratorio de sujetos sanos que conviven con animales y en broncópatas crónicos (9) y podría inhalarse por contacto con secreciones de animales (7). También podría colonizar el tubo digestivo y se ha relacionado con la realización de técnicas invasivas (endoscopias digestivas, válvulas de derivación) como en uno de nuestros pacientes (8). Estos mecanismos justificarían la aparición de bacteriemias sin puerta de entrada evidente. Probablemente, $P$. multocida se comportaría como un patógeno oportunista en sujetos con hepatopatía u otra enfermedad inmunodepresora (1-3). Por tanto, la ausencia de una puerta de entrada no permite excluir a $P$. multocida como causa de bacteriemia en estos pacientes.

\section{J. Campos Franco, R. López Rodríguez, P. Ordóñez Barrosa $^{1}$, M. L. Pérez del Molino ${ }^{1}$, A. González Quintela}

Servicios de Medicina Interna $y^{\prime}$ Microbiología. Hospital Clínico Universitario. Santiago de Compostela

1. Weber DJ, Wolfson JS, Swartz MN, Hooper DC. Pasteurella multocida infections. Report of 34 cases and review of the literature. Medicine (Baltimore) 1984; 63: 133-54

2. Raffi F, Barrier J, Baron D, Drugeon HB, Nicolas F, Courtieu AL. Pasteurella multocida bacteremia: report of thirteen cases over twelve years and review of the literature. Scand J Infect Dis 1987; 19: 385-93.

3. Felix M, Tallon P, Salavert M, Navarro V, Breton JR, Perez-Belles C, et al. Bacteriemia por Pasteurella spp.: una entidad infrecuente durante los últimos 8 años en nuestro centro. Enferm Infecc Microbiol Clin 2003; 21: 334-9.

4. Green BT, Ramsey KM, Nolan PE. Pasteurella multocida meningitis: case report and review of the last $11 \mathrm{y}$. Scand J Infect Dis 2002; 34: 213-7.

5. Layton CT. Pasteurella multocida meningitis and septic arthritis secondary to a cat bite. J Emerg Med 1999; 17: 445-8.

6. Athar MK, Karim MS, Mannam S, Ahmed M. Fatal Pasteurella sepsis and hairy-cell leukemia. Am J Hematol 2003; 72: 285.

7. Jacobson JA, Miner P, Duffy O. Pasteurella multocida bacteremia associated with peritonitis and cirrhosis. Am J Gastroenterol 1977; 68: 489-91.

8. Brivet F, Guibert M, Barthelemy P, Lepicard A, Naveau S, Dormont J. Pasteurella multocida sepsis after hemorrhagic shock in a cirrhotic patient: possible role of endoscopic procedures and gastrointestinal translocation. Clin Infect Dis 1994; 18: 842-3.

9. Ferrer A, Moreno G, Rubio R, Ferrer J. Pasteurelosis respiratoria. Descripción de una primera serie en España. Med Clin (Barc) 1999; 113: 415-7.

\section{Linfoma pulmonar primario: una rara causa de masa pulmonar}

\section{Sr. Director:}

El linfoma pulmonar primario (LPP) se define actualmente como la proliferación clonal linfoide que afecta al parénquima y/o el tejido bronquial de uno o ambos pulmones, sin que se demuestre extensión extrapulmonar en el momento del diagnóstico o en los tres meses siguientes (1). Es una entidad relativamente poco frecuente. Representa el 3-4\% de los linfomas no Hodgkin extranodales, $<1 \%$ de los linfomas no Hodgkin, y sólo el $0,5-1 \%$ de las neoplasias malignas pulmonares (2).

Aportamos el caso de una paciente afecta de LPP que presentó 